\title{
O processo de FormaÇão dos CAMPOS ORGANIZACIONAIS DA CARNE BOVINA E AÇÚCAR ORGÂNICOS E SUAS PERSPECTIVAS
}

Carlos Eduardo de Freitas Vian* Mariusa Momenti Pitelli**

\section{Introdução}

Têm-se verificado nos últimos anos vários problemas sanitários envolvendo alimentos, como a doença da "vaca-louca", colocando em evidência relações econômico-produtivas ocultas em determinadas redes agroalimentares, o que leva a uma reconstrução dessas relações com base em novos padrões de qualidade para poder reestruturar a confiança dos consumidores. A exigência de transparência do sistema de produção nas redes agroalimentares é o principal objetivo do mercado orgânico (STOREL JÚNIOR, 2003).

O termo orgânico, atualmente, é utilizado para produtos ambientalmente diferenciados, porém seu significado se restringe a produtos cujo processo de produção (desde as matérias-primas até produto final) exclui insumos não permitidos como as substâncias químicas sintéticas.

Com base no exposto acima, este trabalho tem por objetivo analisar a dinâmica atual da produção de carne bovina e açúcar orgânicos, demonstrando as especificidades da organização interna das empresas e a necessidade de coordenação das atividades, desde o campo até a venda ao consumidor final.

De acordo com a Instrução Normativa 007/99, do Ministério da Agricultura, Pecuária e Abastecimento (MAPA), considera sistema orgânico de produção agropecuária e industrial todo aquele em que se adotam tecnologias que otimizem o uso dos recursos naturais e socioeconômicos, respeitando a integridade cultural e tendo por objetivo a auto-sustentação no tempo e no

* Professor Doutor do Departamento de Economia, Administração e Sociologia da Escola Superior de Agricultura "Luiz de Queiroz" da Universidade de São Paulo. Email: cefvian@esalq.usp.br

** Mestre em Economia, Doutoranda em Economia - ESALQ USP. Email: mpitelli@esalq.usp.br 
espaço, a maximização dos benefícios sociais, a minimização da dependência de energias não-renováveis e a eliminação do emprego de agrotóxicos e outros insumos artificiais tóxicos, organismos geneticamente modificados (OGM)/transgênicos ou radiações ionizantes em qualquer fase do processo de produção, armazenamento e de consumo, e entre os mesmos privilegiando a preservação da saúde ambiental e humana, assegurando a transparência em todos os estágios de produção e da transformação, visando: 1) A oferta de produtos saudáveis e de elevado valor nutricional, isentos de qualquer tipo de contaminantes que ponham em risco a saúde do consumidor, do agricultor e do meio ambiente; 2) A preservação e a ampliação da biodiversidade dos ecossistemas, natural ou transformado, em que se insere o sistema produtivo; 3) $\mathrm{O}$ fomento da integração efetiva entre agricultor e consumidor final de produtos orgânicos e o incentivo à regionalização da produção desses produtos orgânicos para os mercados locais.

O sistema de produção de carne orgânica está inserido dentro de princípios de agroecossistemas sustentáveis, que engloba dois componentes essenciais: ambiental e social. Este sistema tem como objetivo uma produção que mantenha o equilíbrio ecológico dos agroecossistemas com satisfação das necessidades humanas.

Com base no exposto acima selecionou-se como unidade de análise o "Campo Organizacional”, que leva em consideração as relações comerciais e produtivas entre o vários elos envolvidos, mas também ressalta a importância das relações sociais e políticas. Esta unidade considera o papel dos diversos atores na elaboração das regras de um dado mercado. Desta forma, só podemos entender os produtos orgânicos como fruto das relações entre produtores, certificadores, Estado e Consumidores e da conservação dos interesses dos mesmos.

A produção de carne orgânica privilegia a criação extensiva, que tem como prioridade o bem-estar dos animais, em que há métodos de manejo que dispensam tratamentos veterinários, e tendo como meta a produção de uma carne com qualidade, ou seja, trazer benefícios à saúde das pessoas. Assim, o boi produzido organicamente é uma alternativa de contribuir para a preservação do meio ambiente e ao mesmo tempo oferecer uma carne saudável e natural. $O$ processamento não influi diretamente na denominação de carne orgânica, pois as qualidades do produto não são alteradas.

O açúcar orgânico, produzido a partir da cana-de-açúcar cultivada sem agrotóxicos, vem sendo bastante aceito na Europa, onde o mercado deste produto está crescendo $22 \%$ ao ano. Até recentemente, o açúcar continuava sendo um produto complementar no mercado mundial, que assistia a uma rápida expansão dos alimentos orgânicos. $\mathrm{O}$ mesmo, sendo um produto processado, não tinha condições de ser ofertado diretamente pelos agricultores em grande escala. Neste nicho, o açúcar enfrenta a competição com o mel, um adoçante natural com produção orgânica desenvolvida no mundo inteiro.

Outro fator que explica o desenvolvimento retardado da procura por açúcar orgânico reside na imagem "não salutar" do produto por causa do uso de aditivos químicos no processamento industrial, principalmente no branqueamento do produto, o que o torna menos atraente aos consumidores preocupados com a saúde (STOREL JÚNIOR, 2003).

\section{Revisão de literatura}

\section{Referencial teórico}

Neste tópico trataremos do conceito de "Campo Organizacional" como uma abordagem alternativa para o estudo da dinâmica competitiva no segmento de orgânicos por levar em consideração aspectos sociais e políticos e os interesses dos diversos agentes.

Fligstein $(1990 ; 1996)$ argumenta que os mercados devem ser estudados a partir de um dado contexto social e político, pois existe uma estreita relação entre Estado e Mercado. Os agentes recorrem ao primeiro para estabilizar e ditar as regras de relacionamento entre os vários produtores e destes com seus clientes.

Assim, ele propõe que deixemos de lado as hipóteses de atomismo, relações estritamente comerciais entre os agentes e passemos a analisar o mercado como uma construção social. Deste modo, o papel da sociedade civil se torna relevante para entender a dinâmica competitiva em certas cadeias produtivas, como a de alimentos orgânicos, em que o papel das certificadoras e dos consumidores conscientes é muito relevante e necessário para validar este tipo de diferenciação do produto.

Para ele, as ações estratégicas das empresas visam evitar o embate direto com outras empresas, evitar variações bruscas e inesperadas dos preços de venda e manter a estabilidade estrutural da indústria e do mercado. Assim, Fligstein propõe como hipótese de trabalho que as restrições à concorrência são uma boa forma de controlar os mercados de produtos e serviços mantendo sua estabilidade estrutural e organizacional. Mas esta intervenção só se dá se for de interesse dos grupos organizados, pois os mesmos têm poder político para lutar pela não intervenção.

Assim, ele propõe uma nova unidade de análise, o Campo Organizacional, que é uma alternativa aos conceitos de mercado e indústria baseados em aspectos técnicos. Esta nova unidade é uma construção social e institucional e não visa apenas o entendimento das relações técnicas de produção e formação de preço. No caso dos alimentos orgânicos, estes aspectos ficam evidentes, pois o consumidor não tem capacidade de analisar os atributos do produto 
no ponto de venda, sendo necessário que o mesmo contenha na embalagem um selo de certificação, garantindo que o produto foi produzido e processado segundo as regras ambientais e que estão livres de agrotóxicos.

O Campo Organizacional aparece na definição de Fligstein (1990) como uma arena institucional em que podemos visualizar a interdependência entre os agentes de uma dada cadeia produtiva, envolvendo concorrentes, fornecedores, compradores, fabricantes de produtos substitutos efetivos e potenciais e o Estado ${ }^{1}$. Assim, a unidade de análise relevante não é mais a empresa individual ou as transações feitas por ela, passamos a visualizar todos os agentes envolvidos na dinâmica concorrencial e institucional. Tudo ao mesmo tempo.

Deste modo, esta unidade de análise nos permite ter em mente todos os atores relevantes para o estudo da dinâmica competitiva e da cooperação. Neste aspecto em particular, podemos considerar que o Campo Organizacional traz um avanço teórico à análise da competição e das estratégias, ao pressupor ações cooperativas entre os agentes, além da rivalidade. Isto é importante, pois permitiu uma ligação entre os estudos de estratégias das empresas e os de elaboração de políticas públicas e de coordenação das cadeias produtivas.

Mais uma vez pode-se utilizar os alimentos orgânicos como exemplo. Neste segmento produtivo a confiança entre os produtores agrícolas, empresas de comercialização, consumidores e certificadoras é essencial para garantir a qualidade e confiança dos compradores finais. Deste modo, as relações entre os elos devem ser duradouras e a transparência é essencial.

O Campo Organizacional não pode ser considerado sempre benigno e cooperativo, em muitos momentos as regras são impostas pela força, tamanho e capacidade de controle dos recursos produtivos por certas firmas. Neste sentido, os Campos têm maior capacidade de se imporem e de estabelecerem regras quanto menor for o número de empresas participantes ou se houver uma associação de interesses que materialize o Campo. Este aspecto não se aplica aos produtos orgânicos.

O Campo Organizacional é estruturado pela interação entre as organizações e os atores relevantes. É uma unidade interorganizacional de competição, cooperação e coalizão, permitindo o desenvolvimento da consciência de interdependência e o controle da concorrência ${ }^{2}$. Assim, as organizações tomam decisões parecidas, pois agem com o intuito de manter a estabilidade institucional, influindo na formulação de políticas públicas ou

1. Este conceito aproxima-se bastante do modelo de análise das forças competitivas construído por Porter (1986) por considerar o papel dos produtos substitutos.

$2 \mathrm{O}$ autor destaca o fato de que, em muitos casos, a coerência e o controle da concorrência é obtida pelo exercício da força e poder por parte de um grupo monopolista componente do Campo Organizacional. na forma de autogestão setorial. O Campo permite estabilizar os mercados, sendo que o Estado e as associações privadas (certificadoras) são necessários para manter esta estabilidade. Fligstein coloca como hipótese que quanto maior a participação do Estado e da sociedade civil, maior será o grau de estabilidade dos mercados inseridos em dado Campo. Isto se verifica no mercado orgânico através da atuação do Estado na implementação da legislação pertinente, viabilidade de produção e mais recentemente no auxílio e divulgação dos produtos no exterior. Tudo isto dá grande estabilidade ao Campo Organizacional dos orgânicos, garantindo preços remuneradores e garantia de comercialização da produção.

Segundo Powell e Dimaggio (1991), os Campos Organizacionais se estruturam a partir de um aumento do espaço de interação entre as organizações, o que pode ocorrer pela adoção de uma estratégia semelhante ou pela cooperação ao longo da cadeia. Um outro fator é a emergência de estruturas interorganizacionais de controle dos mercados ou de modelos de coalização estratégica e organizacional, como as certificadoras.

Um terceiro fator de estruturação do Campo Organizacional é o desenvolvimento da consciência da interdependência mútua dos participantes, o que pode ocorrer quando estão envolvidos em um empreendimento comum. Assim, os Campos têm um campo fértil para se desenvolverem durante os momentos de crise. No caso dos orgânicos a consciência da interdependência vem do fato de que todos devem seguir as regras para garantir a qualidade do produto final. Neste caso, há um enforcement das regras de certificação.

Por fim, deve-se destacar que a economia moderna exige dos agentes o manuseio de um grande número de informações, as quais nem sempre são de fácil acesso e que têm custo elevado. Deste modo, a existência de um Campo Organizacional estruturado facilita a obtenção das informações e o controle do comportamento das empresas concorrentes. No caso dos orgânicos, a comercialização é feita através de parcerias, onde o varejo e os produtores dependem uns dos outros e devem compartilhar as informações de mercado, pois os produtos são específicos e não são facilmente substituíveis.

Mas quando um novo agente ingressa no Campo Organizacional a estrutura se altera, porquanto o mesmo pode adotar estratégias competitivas inovadoras, ter acesso exclusivo a agências do Estado, ou ter recursos financeiros abundantes e ou acesso privilegiado a fontes de informações de mercado. Este novo agente pode ser uma agência reguladora que impõe novas regras de conduta e com isso altera as regras do Campo. A estrutura também pode se alterar com a mudança da conduta estratégica das grandes empresas, viabilizando sua maior capacidade de produção e crescimento. Como vimos, isto dificilmente ocorre no mercado de orgânicos, pois as regras são estáveis e o enforcement é alto. 
Segundo Fligstein (1990) e Powell e Dimaggio (1991), o Campo Organizacional tende a ser estável, pois as empresas tendem a adotar estratégias que controlem a concorrência e isto leva à homogeneidade das condutas competitivas. As atitudes só mudam diante das crises ou quando surgem novos interesses, regras ou condutas. Deste modo, explicam a estabilidade institucional e mostram que a mudança é esporádica, pois as organizações buscam a estabilidade estrutural do Campo Organizacional para minimizar a incerteza quanto ao impacto das decisões de investimento e produção.

Os autores denominam este processo de isomorfismo organizacional do Campo, classificando-o de duas formas: o competitivo é fruto da adoção de estratégias semelhantes com o objetivo de controlar a concorrência; já o Institucional é fruto dos aspectos políticos e econômicos que constrangem as ações das empresas de um dado campo.

No caso dos orgânicos o isomorfismo é gerado pelo enforcement das regras de certificação e da legislação federal sobre orgânicos. A partir destas duas tipologias podemos perceber que o Campo Organizacional se situa em um nível mesoinstitucional, ou seja, podemos agrupar as empresas de um mesmo setor por tipo de estratégia adotada, açúcar orgânico e carne orgânica, por exemplo, sendo que elas concorrem pela colocação de seus produtos junto a um mesmo público alvo, negociam com os mesmos compradores, e estão sujeitas às mesmas regras de produção e qualidade do produto, necessitam da participação de agências reguladoras e certificadoras e podem vir a criar uma associação ou sindicato de produtores. Por outro lado, as empresas que produzem açúcar ou carne convencional formam outros Campos Organizacionais e assim por diante.

A argumentação acima pode ser melhor entendida analisando-se a Figura 1. O isomorfismo institucional pode ser imposto pelo Estado através da política econômica e da legislação (setas descendentes na Figura 1). Este processo obriga as organizações a seguirem procedimentos padrão. Então, a conduta se altera, ou não, quando o Estado é influenciado por pressões de novos atores, que surgem esporadicamente, ou pelos já existentes ${ }^{3}$ (setas ascendentes na Figura 1).

Mas por outro lado, a Figura 1 deixa evidente que a regulação e os incentivos para a adoção das regras institucionais não precisam ser impostos pelo Estado, podem ser fruto da auto-regulação dos Campos Organizacionais, através de entidades que sejam reconhecidas pelas empresas e pela sociedade.

3. Um exemplo empírico deste fato foi a luta da Fiat para viabilizar o lançamento de automóveis 1.0. Posteriormente, as outras montadoras beneficiaram-se deste empenho.
Como exemplos podemos citar o Instituto Biodinâmico (IBD), Greenpeace, Associação de Agricultura Orgânica (AAO), Associação Brasileira dos Produtores de Animais Orgânicos (ASPRANOR) e ECOCERT no caso dos alimentos orgânicos no Brasil. No âmbito internacional destaca-se a International Federation of Organic Agrilculture Moviment (IFOAM) USDA Organic, Japan Agriculture Standard (JAS), entre outras. Mas todas estão sujeitas às mesmas regras trabalhistas, fiscais e de comercialização.

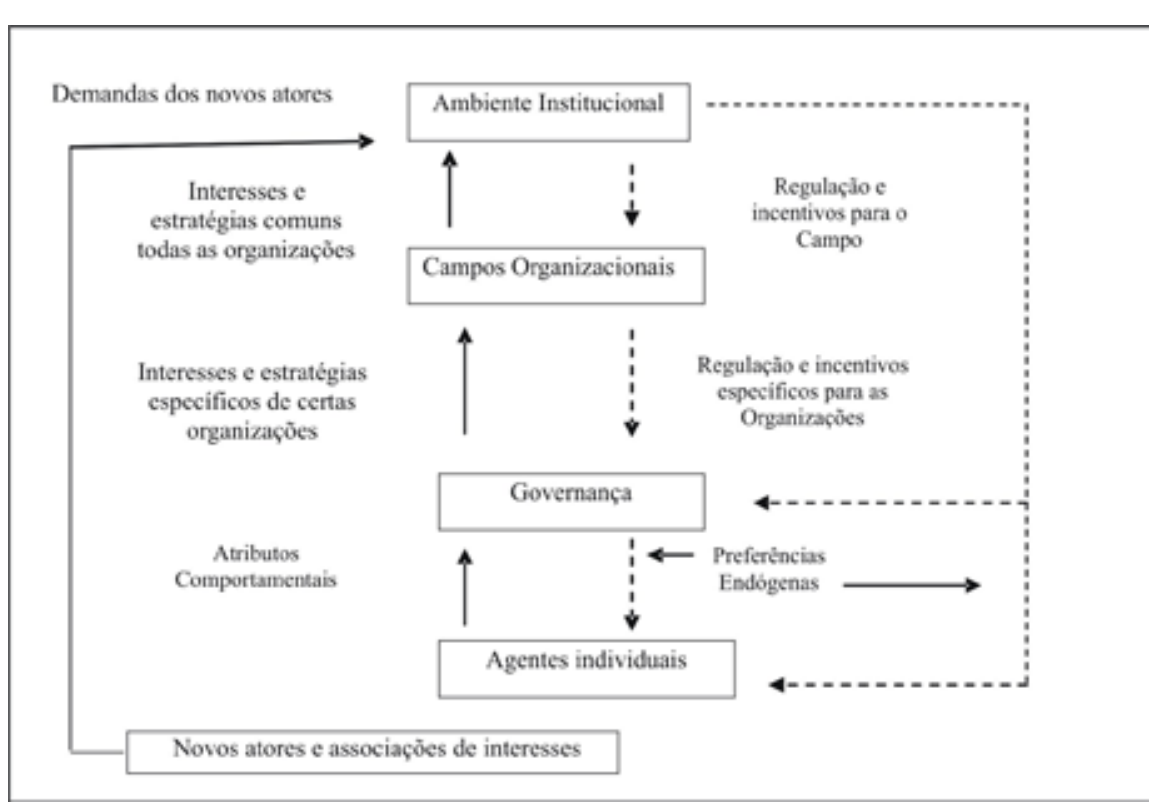

Figura 1. Esquema Modificado de Três Níveis das Relações entre os níveis Macro, Meso e Microinstitucional. Fonte: Elaboração dos autores a partir de Williamson (1993)

O próximo tópico será dedicado a traçar um panorama geral da comercialização de alimentos orgânicos, com ênfase na dinâmica dos Campos Organizacionais do Açúcar Orgânico e da Carne Bovina Orgânica.

\section{Panorama do mercado de produtos orgânicos}

A Figura 2 mostra os principais componentes do Campo Organizacional de orgânicos. Nota-se que se pouco se diferencia das demais cadeias agroalimentares, a não ser pela presença da figura da certificação, que tem importante papel na conformação do Campo Organizacional de alimentos orgânicos, uma vez que a sua credibilidade é determinante da confiança que distribuidores e consumidores devotam ao produto oferecido. Também se 
verifica a inexistência da figura do atacadista - em função da pequena escala de produção - ou do intermediário entre a produção e o próximo elo.

Os produtos orgânicos têm uma participação ainda pequena no mercado de alimentos. Segundo a OMC (Organização Mundial do Comércio), estes alimentos devem atingir cerca de $10 \%$ do mercado total nos próximos anos.

Apesar das informações sobre sua participação no mercado mundial serem imprecisas, e de que até início de 2002 não existiam dados consolidados sobre o volume e o valor de produtos orgânicos comercializados no mundo, $o$ Centro Internacional de Comércio (ITC) estima que esse mercado movimentou em 1997 valores próximos a US\$ 10 bilhões, sendo os Estados Unidos, Japão e Europa os maiores mercados. Essas três regiões tiveram um volume de negócios nesse segmento de US\$ 13 bilhões em 1998 e US\$ 20 bilhões em 2004. (IBD, 2005; BNDES SETORIAL, 2002).

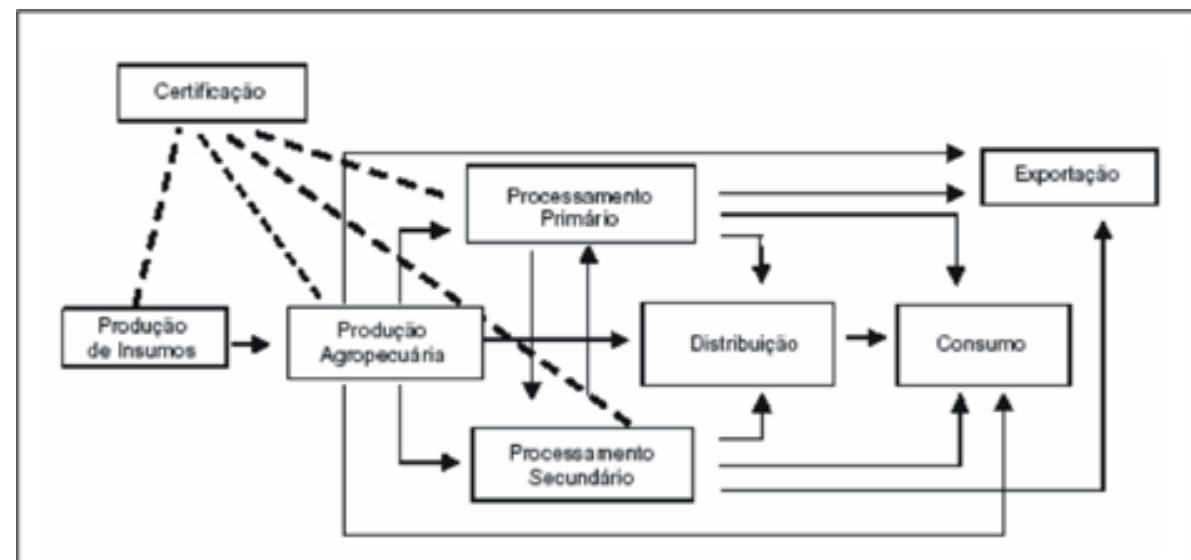

Figura 2. Campo Organizacional de Orgânicos. Fonte: BNDES, 2002.

Quanto ao consumo, segundo a Agra Europe (empresa inglesa especializada em informações para a indústria alimentícia), o consumo de alimentos orgânicos tem crescido, nos últimos 10 anos, a taxas próximas de $25 \%$ ao ano na Europa, nos Estados Unidos e no Japão, estimando que alcance $15 \%$ do consumo total de alimentos (BNDES SETORIAL, 2002).

No Brasil, a produção orgânica, estimada pelo ITC e IBD em 1998, foi, respectivamente, de US\$ 90 milhões e US\$ 150 milhões. Os dados compilados permitem uma estimativa de valor de mercado da produção brasileira de orgânicos na faixa de US\$ 220 a US\$ 300 milhões, dependendo da performance de produtividade de frutas e palmito e da margem aplicada pelos distribuidores.
A tabela 1 mostra os produtos com maiores áreas de produção orgânica e os respectivos números de produtores. Nota-se que frutas, cana-de-açúcar e palmito são os produtos mais importantes. O primeiro caso (fruta) é resultante da junção dos mais diversos tipos de cultivo (açaí, acerola, banana, caju, côco, goiaba, laranja, limão, maçã, mamão, manga, maracujá, melão, morango, pêssego, tomate e uva). A cultura de palmito tem manejo semelhante ao processo extrativista, demandando grandes extensões territoriais, e a canade-açúcar também requer grandes áreas para produção em escala comercial, embora existam casos de pequenos produtores de açúcar mascavo.

A partir dos anos 90, os supermercados e a indústria empenharamse em participar deste mercado, incluindo na lista uma ampla variedade de alimentos e bebidas processados. Sendo um ingrediente importante na produção de sorvetes, geléias, panificação e confeitaria, o açúcar começou a desfrutar de uma procura crescente por parte da indústria processadora de alimentos orgânicos. Para o biênio 1998/99, a produção mundial de açúcar orgânico foi estimada em 40 mil toneladas. Os recentes desenvolvimentos, tanto no fornecimento como no lado da procura, ilustram um imenso potencial no longo prazo (VIAN, 2003).

Verifica-se também que a quantidade de processados ainda é relativamente pequena, sendo os produtos de maior destaque: café, açúcar, suco de laranja, castanha-de-caju e óleos vegetais.

Tabela 1. Culturas com Maiores Áreas de Produção sob Manejo Orgânico e Número de Produtores.

\begin{tabular}{lrr|lrr}
\hline PRODUTO & $\begin{array}{c}\text { NÚMERO DE } \\
\text { PRODUTORES }\end{array}$ & $\%$ & PRODUTO & AREA (ha) & $\%$ \\
\hline Soja & 593 & 8,40 & Frutas & 30.364 & 11,26 \\
Hortaliças & 549 & 7,77 & Cana-de-Açúcar & 30.193 & 11,19 \\
Café & 419 & 5,93 & Paimito & 20.816 & 7,72 \\
Frutas & 273 & 3,87 & Café & 13.005 & 4,82 \\
Paimito & 40 & 0,57 & Soja & 12.516 & 4,64 \\
Cana-de-Açúcar & 18 & 0,25 & Hortaliças & 2.989 & 1,11 \\
Milho & 6 & 0,08 & Milho & 264 & 0,10 \\
Processados & 127 & 1,80 & Processados & - & - \\
Outros + Pasto & 5.038 & 71,33 & Outros + Pasto & 159.571 & 59,16 \\
\hline Total & 7.063 & $\mathbf{1 0 0 , 0 0}$ & Total & $\mathbf{2 6 9 . 7 1 8}$ & $\mathbf{1 0 0 , 0 0}$ \\
\hline
\end{tabular}

Fonte: BNDES Setorial, 2002.

REVISTA UNIARA, n.20, 2007 121 
No entanto, informações da Associação Brasileira de Pecuária Orgânica (ABPO) apontam que a área e o número de produtores que se dedicam no Brasil à produção orgânica é bem maior. Segundo essa associação, há um rebanho bovino de aproximadamente 210 mil cabeças e como o manejo por esse sistema exige um mínimo de 2 ha por cabeça, conclui-se, então, que a pecuária orgânica no Brasil ocupa uma área próxima de 420 mil ha, número bastante superior aos 116 mil ha certificados até o momento pelas entidades consultadas (BNDES Setorial, 2002). Desta forma, pode-se inferir que existem produtores que ainda não concluíram seu processo de certificação e que por isso devem comercializar a produção como convencional.

Estima-se que as vendas mundiais de açúcar orgânico atinjam pelo menos 190 mil toneladas em 2005. O Grupo Balbo tem potencial para produzir 70 mil toneladas por $\mathrm{ano}^{4}$, o que demonstra o que o Brasil é hoje o maior produtor mundial de açúcar orgânico (VIAN, 2003).

\section{Certificação}

A certificação é um processo que inspeciona e orienta a produção e o processamento de alimentos de acordo com normas e práticas de produção orgânica, garantindo ao consumidor a procedência de alimento isento de toxinas, cuja produção é feita respeitando o meio ambiente. Este processo é feito por auditorias independentes, por um terceiro agente que não o produtor e nem o consumidor.

O que leva um consumidor a preferir um produto orgânico em relação aos demais é a informação sobre suas vantagens nutricionais, a ausência de toxicidade e a confiança de que foi produzido conforme os preceitos que preservam esses fatores.

No Brasil, a certificação teve origem informal, através do trabalho desenvolvido por organizações não-governamentais, como associações e cooperativas de produtores e consumidores, mas à medida que iniciaram suas exportações de orgânicos, houve a necessidade de certificar seus produtos por instituições de reconhecimento internacional passando, assim, a obedecer aos padrões internacionais de certificação.

Assim, o governo brasileiro baixou a Instrução Normativa $n^{\circ} 007$, de 17 de maio de 1999, que orienta as normas das certificadoras nacionais para a produção de produtos orgânicos vegetais e animais (IBD e MAPA)

Quanto ao boi orgânico, têm-se as seguintes características: criado a pasto, sem agrotóxico; adubação verde, proibição do uso de uréia; confinamento somente 90 dias antes do abate; suplementação com alimentos

4. A Univalem, produtora do Zucc, tem potencial para 10 mil toneladas. de origem exclusivamente vegetal, dos quais $80 \%$ orgânicos; pode utilizar sal mineral; medicamentos homeopáticos, fototerapia e acupuntura contra parasitas, antibióticos são proibidos; é proibida a transferência de embriões; área de criação deve estar de acordo com normas ambientais.

O açúcar orgânico exige que a cana-de-açúcar seja produzida de forma orgânica em área livre de defensivos e fertilizantes químicos e que tenha passado por um período de quarentena para eliminação de resíduos (STOREL JÚNIOR, 2003). Na fase industrial, a cana orgânica deve ser processada separadamente, sendo que uma parcela da matéria-prima serve para "limpar" a indústria dos resíduos da matéria-prima convencional. Deste modo, as empresas que produzem os dois tipos de açúcar costumam processar o orgânico no final da safra (VIAN, 2003).

As usinas brasileiras interessaram-se por este mercado e investiram na produção de açúcar orgânico desde meados dos anos 90. As primeiras cargas foram exportadas para a Europa em 1998. O Brasil tornou-se o maior produtor deste alimento, fazendo com que pequenas empresas das Ilhas Maurício e da África do Sul, pioneiras no segmento, fechassem suas portas por não poderem fazer frente ao preço praticado pelos brasileiros. Aqui, as pioneiras neste segmento foram as usinas São Francisco (Sertãozinho) e Univalem (Valparaíso), seguidas recentemente pela Albertina (Sertãozinho), que já descontinuou a produção e por unidades de outros estados. (VIAN, 2003; STOREL JÚNIOR, 2003).

\section{Metodologia}

Este trabalho traz os resultados de uma pesquisa exploratória sobre a estrutura e dinâmica dos Campos Organizacionais de alimentos orgânicos, com ênfase na carne bovina e no açúcar.

Primeiramente realizou-se uma revisão de literatura sobre a produção de alimentos orgânicos no Brasil, com o objetivo de definir o que são alimentos orgânicos, as organizações envolvidas e a legislação sobre o tema.

Com a constatação de que seriam necessários dados primários para embasar alguns dados secundários obtidos, elaborou-se um questionário enfocando a produção, processamento, armazenamento de orgânicos e inspeção da produção e processamento por parte das certificadoras e associações de produtores.

Este questionário foi enviado a todas as empresas produtoras de carne bovina e de açúcar orgânicos, sendo que se obteve um retorno de $100 \%$ dos questionários enviados. Este fato se deve ao pequeno número de empresas que atuam neste segmento. Além dos processadores, foram obtidos dados de uma certificadora renomada e de uma associação de produtores de bovinos orgânicos. Devemos ressaltar que no caso do açúcar orgânico não foram 
identificadas associações de produtores ou processadores.

Os resultados desta pesquisa serão discutidos abaixo e em seguida serão analisadas as possíveis tendências destes Campos Organizacionais e levantadas algumas questões, que deverão ser aprofundadas em pesquisas posteriores.

\section{Resultados}

Primeiramente discutiremos os resultados obtidos sobre a produção de carne bovina orgânica. Em seguida abordaremos ao Campo Organizacional do açúcar orgânico e finalizando, faremos uma breve comparação entre eles e apontaremos os principais problemas e oportunidades para cada um.

\section{Carne bovina orgânica ${ }^{5}$}

Do universo de empresas frigoríficas pesquisadas foram identificadas três que são certificadas para processar a carne bovina orgânica, sendo que uma delas cessou esta atividade em 2001, por motivos não informados. Todas as empresas processam a carne orgânica e convencional nas mesmas instalações, o que tem implicações em termos de planejamento e controle do abate. Este aspecto será retomado mais adiante e será um ponto de comparação importante com o açúcar orgânico.

Quanto à fonte de fornecimento do boi orgânico, as empresas responderam que são fazendas certificadas para criar este tipo de animal, dentre eles o IBD e a ASPRANOR. Dentre os frigoríficos pesquisados, um deles indicou que é integrado para trás, visto que cria animais em fazendas próprias.

Quando à certificação da agroindústria processadora da carne, as respostas indicam que o IBD é o principal certificador por ser pioneiro nesta atividade no Brasil e por seu reconhecimento internacional, sendo filiado às principais entidades internacionais de certificação orgânica, como o IFOAM e a JAS, o que é necessário para se exportar para os principais blocos econômicos, como União Européia, NAFTA e Japão.

O IBD segue a legislação federal em vigor (Instrução Normativa 007 de 1999) e também está em consonância com a legislação internacional, garantindo que os produtos serão aceitos e que tenham acesso à certificação sanitária, além da de produto orgânico. Para isso o IBD emite o "Certificado Anual" que qualifica o projeto e o produto como orgânicos de acordo com o período de validade estabelecido neste documento (um ano). No mesmo também consta se o produto atende às exigências de mercado interno e externo ou apenas de um deles.

5. Neste tópico os nomes das empresas serão mantidos em sigilo por exigência das mesmas.
A certificadora também exige que o frigorífico e o criador apresentem a documentação de rastreabilidade dos animais a serem abatidos. Segundo o IBD o fornecimento desta documentação é o ponto mais delicado na certificação e inspeção esporádica dos frigoríficos. A falta da mesma pode fazer com que os bovinos não recebam o selo orgânico.

O "Certificado Anual" qualifica a empresa que o possuí como produtora de orgânicos e pode ser utilizado nos contatos comerciais, mas não garante, por si só, a qualidade de toda a produção.

Em função disto, o IBD fornece o "certificado de transação", cuja função é atestar o status da carga comercializada, ou seja, comprova a qualidade orgânica e a fiscalização de determinado lote de produto. Este certificado deve ser fornecido ao cliente junto com o Certificado Anual, demonstrando que a empresa e o produto foram fiscalizados pelo IBD e dando garantias ao consumidor da qualidade e características do produto comprado.

A certificadora exige que as empresas atendam aos requisitos sanitários para exportação e que encaminhem previamente os documentos de programação de abate de bovinos orgânicos, sendo que há outras exigências feitas diretamente ao produtor dos animais, como vimos acima.

Quanto ao abate, a certificadora exige que haja uma separação dos bovinos orgânicos dos não orgânicos, o que é possível pelo fato de que todos os animais são de origem certificada via Guia de Transporte Animal (GTA) e nota fiscal, o que permite a separação dos oriundos de propriedades orgânicas das demais.

Para garantir a qualidade orgânica e impedir a mistura com produto convencional a certificadora faz uma inspeção anual nos frigoríficos, que deve coincidir com o abate e processamento de animais e carne orgânicos. Assim, todo o processamento é fiscalizado pelos técnicos da certificadora. Ressalta-se também que existem inspeções surpresa ao longo do ano, evitando a possibilidade de comportamento oportunista por parte da empresa e uso indevido do selo.

Antes do início do abate e processamento de bovinos orgânicos o frigorífico deve passar por uma limpeza para evitar contaminação por parte da carne convencional. Na escala de abate, os orgânicos são os primeiros a serem abatidos e recebem o carimbo ORG. Os animais identificados por esta sigla são separados em lotes segundo o proprietário, encaminhados a currais específicos onde serão inspecionados pelo Serviço de Inspeção Federal, que é a mesma do gado convencional e que tem por objetivo evitar o abate de bovinos doentes, zelando pela segurança do alimento.

Ressalta-se que a fiscalização do Ministério da Agricultura é permanente, enquanto a da certificadora é esporádica, embora o abate e processamento de bois orgânicos só ocorram com a presença da certificadora. 
Segundo a ASPRANOR o abate e processamento também são acompanhados por um veterinário pago por esta associação que emite relatórios visando o aperfeiçoamento da qualidade do produto. Os quesitos avaliados por este profissional são: 1) os procedimentos do frigorífico; 2) a espessura da cobertura de gordura e a sua uniformidade; 3 ) nível de contusões, lesões de vacinas e outras lesões; 4) peso dos animais e uniformidade do lote.

$\mathrm{Na}$ fase de desossa, as carcaças de animais orgânicos também são as primeiras a serem desossadas e em seguida os diversos tipos de carnes são identificados como ORG com uma etiqueta especial, que acompanha o produto até a embalagem. Uma das empresas pesquisadas relatou que existem dias pré-determinados para o abate dos animais orgânicos, uma vez que a certificadora deve estar presente para fiscalizar o processo.

Os lotes de carne orgânica, identificados pela sigla ORG são armazenados nas câmaras frias, em Boxes separados e identificados até o momento do embarque e distribuição. Há uma separação total do produto convencional. Os procedimentos de embarque são fiscalizados pelo Controle de Qualidade de cada frigorífico. Depois do processamento da carne orgânica, existe um processo de limpeza e fiscalização para evitar que peças de carne orgânica se misturem com as convencionais.

Pode-se perceber que a conscientização da mão-de-obra envolvida neste processo é de suma importância. Uma das empresas pesquisadas dedicou muitos recursos ao treinamento do pessoal que participa do processamento da carne orgânica e investe constantemente em mensagens sobre este assunto em seus meios de comunicação internos.

Quanto à comercialização deste produto, as empresas relataram que o mercado externo ainda é pequeno pelo fato da oferta de gado orgânico ser limitada, o que impede o fechamento de contratos a longo prazo. Segundo o IBD o Brasil está abatendo cerca de 500 animais orgânicos por mês. A Austrália e a Argentina produzem mais do que o Brasil.

Uma das empresas exporta apenas cortes nobres de carne orgânica e comercializa o restante no mercado interno como carne convencional. Outra comercializa carne orgânica tanto no mercado interno como no externo, e a terceira, que deixou de produzir, apenas no mercado externo. Ressalta-se que a preferência pelo mercado externo se deve à maior lucratividade proporcionada pelo maior preço obtido nestes negócios, pois no exterior o mercado já está consolidado, o consumidor é consciente da qualidade e preço. No mercado interno ainda são necessários muitos investimentos em campanhas de conscientização e divulgação do papel das certificadoras e da importância dos selos para garantia de qualidade e processo.

Segundo a ASPRANOR, as exportações brasileiras são limitadas pela falta de produtores certificados, embora o mercado externo seja promissor e garanta alta rentabilidade aos produtores.
Percebe-se assim, que o Campo Organizacional da carne orgânica ainda não se consolidou, existindo ainda uma lacuna quanto ao tamanho do mercado consumidor e às suas exigências, principalmente no Brasil. Neste ano, o Ministério do Desenvolvimento Agrário lançou campanha institucional visando conscientizar os consumidores sobre as qualidades dos produtos orgânicos, visto que grande parte da população ainda desconhece o produto, não entende o significado do selo, etc. Por outro lado, a ASPRANOR está se associando a várias ONGs para implantar projetos na área ambiental e social, as quais fazem parte do conceito de orgânico.

Outro fator a ser salientado é a afirmação do representante da ASPRANOR de frente à impossibilidade de venda do gado orgânico no mercado interno ou para exportação, os criadores comercializam estes bovinos como convencionais, uma vez que o preço recebido pelo boi orgânico varia de 7 a $20 \%$ a mais do que o do convencional. Desta forma, este tipo de negócio pode não dar lucro, as cobre boa parte dos custos de produção.

Pode-se inferir do exposto acima que as grandes margens de lucro estão ficando nas mãos dos varejistas e não do produtor. Isto pode vir a inviabilizar a produção e causar desinteresse dos pecuaristas.

No que tange ao mercado externo, os produtores apontam a carência de projetos ou incentivos do Estado no sentido de estimular as exportações, visto que este destino ainda é o que pode possibilitar o crescimento da atividade no curto prazo, já que o mercado interno ainda é limitado por conta do exposto acima. Segundo representante de um dos frigoríficos entrevistados, a carne orgânica enfrenta as mesmas barreiras sanitárias da carne in natura brasileira, devido aos problemas com febre aftosa. Neste contexto, o Estado também poderia atuar de forma a negociar a liberação da carne orgânica dessas barreiras, viabilizando a ampliação das vendas externas e a entrada em mercados mais exigentes, como o dos Estados Unidos, Japão e Coréia do Sul.

No próximo tópico trataremos do Campo Organizacional de açúcar Orgânico com um pouco mais de detalhe em alguns aspectos, visto que este setor tem sido objeto de vários estudos devido ao volume de produção.

\section{Açúcar orgânico}

Como exposto acima, a produção de açúcar orgânico no Brasil remonta aos anos 90. A empresa pioneira neste segmento foi a Usina São Francisco do Grupo Balbo. O açúcar orgânico Native é fabricado por esta empresa e exportado desde de 1998, primeiro para os Estados Unidos e depois para a Europa. O produto só chegou ao mercado interno em 1999, com pré-lançamento durante a Feira de Utilidades Domésticas (UD 99) daquele ano, onde foram distribuídos ao público 50 mil saches de 7 gramas (VIAN, 2003). 
A Usina São Francisco tem cerca de $58 \%$ do mercado mundial de açúcar orgânico, avaliado atualmente em 40 mil toneladas. O produto é distribuído no exterior pela rede Global Organic, atendendo a 34\% dos consumidores europeus e a 50\% dos americanos. A produção começou em 1997 com 1,6 mil toneladas. Em 1998 o volume de produção foi de 4 mil toneladas, e em 1999 de 23 mil toneladas (VIAN, 2003).

O Grupo Balbo não usa a marca Native no exterior, apenas exporta o produto que é empacotado por refinadores, fabricantes e distribuidores de alimentos orgânicos que compõem a Global Organic e que estão nos EUA, México, Canadá, Alemanha, Itália, França, Espanha, Bélgica, Dinamarca, Holanda, Reino Unido, Suíça, Suécia, Finlândia, Noruega, Nova Zelândia, Tunísia e Japão. Pode-se destacar entre as indústrias alimentícias, clientes da São Francisco, a Newman's Own, do ator norte-americano Paul Newman.

O Grupo Balbo ampliou a sua atuação no mercado de orgânicos com a produção de café e planeja ampliar suas atividades para se tornar uma indústria de vários tipos de alimentos orgânicos. O caminho foi aberto com a produção de açúcar orgânico seguido pelo café e derivados e deve prosseguir na área de produtos alimentícios em que o produto tenha grande peso, como os achocolatados e outras misturas secas.

A Usina São Francisco utiliza toda a sua capacidade produtiva para o açúcar orgânico o que facilita o gerenciamento da produção e permite que a empresa forneça produtos o ano todo e impede que ocorram problemas de mistura do produto tradicional com o orgânico e vice-versa.

O produto da Usina São Francisco concorre com o Zucc da Univalem, de Valparaíso ${ }^{6}$ (SP), que está concentrando esforços na produção de açúcar orgânico e para o fornecimento de melaço para a fabricação de ciclamato monossódico (marca Ajinomoto) (VIAN, 1997). O Zucc tem o selo do IBD.

O programa de açúcar orgânico da Univalem foi implantado em 1992. Um dos diferenciais em comparação com a produção convencional está na preparação do solo. No caso da usina, houve um processo de desintoxicação das terras durante quatro anos. Em alguns casos este prazo pode ser maior ou menor dependendo do nível de saturação de químicos no solo. (STOREL JÚNIOR, 2003)

A fertilização é feita com nutrientes naturais extraídos da própria cana-de-açúcar, como a vinhaça e a torta de filtro, e com 3 mil toneladas de esterco bovino, pois no plantio da cana orgânica é proibida a utilização de produtos químicos. Todo o volume é proveniente da F. Sales Agropecuária, de

6. Adquirida em meados de 2001 pela Franco-Brasileira Açúcar e Álcool S.A (FBA), uma associação entre grupo brasileiro COSAN, a francesa Union SDA e a trading Sucden.
Valparaíso, onde são criadas 9 mil cabeças de gado para corte em regime de confinamento. Segundo a diretoria da empresa, cada animal consome 20 quilos de ração (bagaço de cana fornecido pela Univalem, mais milho e soja) (VIAN, 2003). O cultivo orgânico não utiliza produtos químicos, pois as pragas são combatidas biologicamente a partir da produção de predadores naturais no laboratório da empresa.

Para obter o certificado do IBD, a Univalem também teve o processo industrial fiscalizado e teve que participar de projetos de recuperação e preservação da natureza. Em 1997, a empresa plantou 15 mil árvores nativas, sob a orientação da Companhia Energética de São Paulo (Cesp), na área de preservação permanente do rio Aguapeí e córrego Sapé, em Valparaíso. Em 2001 foram outras 62 mil árvores nativas nas nascentes dos córregos Sapé e Lajeado, com apoio da CESP e da Flora Tietê.

A cana-de-açúcar utilizada para a fabricação do Zucc, por exemplo, é cultivada com processos naturais, como a utilização de adubo orgânico, o cultivo de leguminosas nas entrelinhas da cana, a distribuição de vinhaça pelos canaviais e a rotação das culturas para evitar erosões e eliminação das queimadas. Todo este processo é fiscalizado pelo IBD através da inspeção anual e de surpresa e da emissão de certificados anual e de transação.

A Univalem foi adquirida em meados de 2000 pela FBA, e esta anunciou que a produção do ZUCC seria transferida para a Usina Santo Antônio, de Piracicaba, arrendada por 18 anos a partir de 2001. O principal motivo desta transferência seria logístico. Piracicaba está mais próxima do porto de Santos e a produção estaria na mesma região em que outras empresas da FBA já estão instaladas, facilitando a administração e o controle. A produção orgânica em Piracicaba também seria estratégica para o grupo, pois o preço final pode viabilizar o corte manual da cana crua em propriedades que não são adequadas à mecanização. Mas esta transferência não se efetivou e a produção de orgânicos continua na Univalem. A pesquisa de campo que subsidiou este trabalho não permitiu obter informações sobre a produção de cana orgânica em Piracicaba.

A Univalem exportou, em 1999, 4 mil toneladas para Inglaterra, Bélgica, Alemanha, Suíça, Holanda, a um preço, FOB Santos, de U\$ 480 a tonelada. As perspectivas são de atingir 20 mil toneladas no médio prazo. O principal destino é a indústria de alimentos, particularmente de bolos, biscoitos e doces. 95\% da produção seguiu para os países europeus, onde o consumo é crescente. O preço da tonelada de açúcar orgânico na Europa, em torno de US\$ 500 tende a crescer conforme o comportamento do mercado.

O Zucc foi o primeiro açúcar orgânico com selo Greenpeace ao lado de produtos não-orgânicos, tais como café, açúcar, grãos e sucos, pois segundo Roberto Kishinami, diretor-executivo do Greenpeace Brasil (VIAN, 2003) a 
organização pretende ampliar sua atuação em cima dos produtos orgânicos e aproveitar a brecha para combater os transgênicos. O Zucc apostou na força do selo Greenpeace orgânico e na certificação do Instituto Biodinâmico de Botucatu, que atestam que o produto foi fabricado sem agredir o meio ambiente e sem a utilização de produtos químicos para atender também o mercado interno. Esperava-se ganhar participação de mercado, mesmo com o preço mais elevado do que o do produto convencional, pois o orgânico é cerca de $325 \%$ mais caro.

Mas com a dinâmica atual do Complexo Agroindustrial Canavieiro e a fusão com a FBA o ZUCC deixou de ser comercializado internamente e deu lugar ao açúcar orgânico Da Barra.

A Univalem não processa apenas a cana orgânica, o que faz com que seja necessário planejar a produção de forma que esta matéria-prima seja produzida em batelada, sendo que se exige que durante seis horas a cana orgânica produza açúcar que será vendido como convencional, visto que estará contaminado com produtos químicos oriundos da matéria-prima anterior. Isto permite que se intercale a produção de açúcar convencional com orgânico, embora gere perda de matéria-prima, mas a empresa prefere produzir o orgânico em uma batelada só. Em 1995 foram destinados 25 dias de safra para o esmagamento da produção de 170 hectares de cana orgânica. Atualmente a empresa possui 3000 hectares certificados. Todo este processo é fiscalizado por profissionais do IBD.

No campo da comercialização a Univalem coordenou a criação da Ecolínea, uma empresa de distribuição de produtos orgânicos, viabilizando a comercialização da produção de pequenos produtores espalhados por várias regiões do Brasil. As empresas rateiam as despesas de distribuição e promoção dos produtos nos pontos de venda ao consumidor. A Ecolínea distribui o Zucc, geléias, vinagre e aceto balsâmico, café, mel, balas e doces, azeite de oliva, caldo de cana e molho de tomate. A pesquisa de Campo realizada para este trabalho não trouxe maiores informações sobre a Ecolinea, mas aparentemente ela ainda existe para comercializar outros produtos.

Contudo, o preço desta alimentação é, em média, 50\% mais caro, comparado com os baseados em produtos convencionais, segundo dados do Greenpeace. Isto talvez explique o resultado de um levantamento com a marca que foi reconhecida espontaneamente por $17 \%$ da população das classes A e B. Na consulta induzida, este reconhecimento saltou para 67\%. (VIAN, 2003).

Prova da identificação da marca com este público está no fato de o lançamento do Zucc ter ocorrido em um dos bairros mais nobres de São Paulo, no bem decorado Espaço Greenpeace. Assim, percebe-se que o açúcar orgânico é um produto caro e restrito (VIAN, 2003).

A Usina Albertina também atuou no segmento orgânico, mas descontinuou a produção em virtude de problemas de escala e de organização da produção. A empresa iniciou o processo de adequação da produção em 1994 e colocou o produto à disposição da indústria de alimentos e para exportação. No varejo pretendia-se lançar a marca Amazon, mas a mesma não chegou a ser comercializada.

A Albertina gerenciava a produção de orgânico de forma diferente da São Francisco, fabricando o orgânico em uma batela só no início ou no final da safra, o que têm implicações importantes em termos de armazenagem do produto, comercialização e produtividade industrial. Em geral no início da safra a cana não atingiu o ponto ideal de maturação e produz menos açúcar. No fim da safra, as chuvas dificultam a colheita e o transporte, prejudicando a produção do açúcar. O processamento devia ser agendado com a certificadora para que a fiscalização pudesse ocorrer.

Segundo Storel Júnior (2003) mais três usinas estão iniciando a produção de orgânico. Uma na Bahia e duas em Goiás, sendo que as mesmas deverão dedicar apenas alguns dias de sua produção total ao orgânico, pelo menos inicialmente.

Percebe-se que o Campo Organizacional do açúcar orgânico está em conformação e ainda não se estabilizou, sendo que as iniciativas das empresas podem ser revertidas diante de um mercado que ainda tem pequena escala. Deste modo, o acompanhamento deste processo é de suma importância.

\section{Comparação entre os casos}

Com base no exposto acima, verifica-se que na produção de carne bovina orgânica há uma separação dos bovinos orgânicos dos convencionais orgânicos são identificados pelo carimbo ORG - e no abate eles são os primeiros a serem abatidos e desossados. Na produção de açúcar orgânico também há uma separação da cana-de-açúcar orgânica das não orgânicas, e no processamento ocorre um planejamento da produção, onde algumas empresas optam pela intercalação da produção de açúcar convencional e orgânico, enquanto que outras preferem produzir em uma batelada só no início ou no final da safra.

Em relação ao atendimento de mercados, as empresas produtoras de carne bovina orgânica e as empresas produtoras de açúcar orgânico destinam sua produção ao mercado interno e externo, porém é o mercado externo que tem maior relevância em função do maior poder aquisitivo do consumidor dos países desenvolvidos. Mas ainda existem problemas sanitários com a carne in natura que impedem a colocação da carne orgânica em alguns mercados relevantes, como Estados Unidos e Ásia.

Nota-se que há uma organização tanto no processamento da carne como no de açúcar orgânicos, com o objetivo de certificar a origem e características do produto. Estes procedimentos encarecem o produto final, o que contribui para sua comercialização em mercados de alto poder aquisitivo. 
Por outro lado, constata-se que a fiscalização da certificadora sobre a carne bovina orgânica é esporádica, porém de forma rígida, o que impede que existam abates e processamento sem a presença de um profissional da certificadora. Isto impossibilita que haja incerteza quanto às características e origem da carne, o que daria brecha a comportamentos oportunistas.

Tendo como base a conceituação de Campo Organizacional feita na segunda parte deste trabalho, pode-se concluir que a criação e o processamento de bovinos orgânicos se caracterizam como um Campo Organizacional, mas o mesmo ainda não está consolidado e pode ser inviabilizado pela distribuição desigual dos ganhos advindos da comercialização deste produto diferenciado, o que pode afetar a oferta de bovinos visto que as margens de lucro dos produtores não são significativas em relação às obtidas pelos demais elos. Outro fator de instabilidade é o fato de que as barreiras à entrada neste segmento ainda são pequenas e a concorrência desenfreada pode levar alguns criadores a desistirem do negócio por causa do baixo retorno.

No caso do açúcar orgânico, as respostas sobre a fiscalização das certificadoras não foram conclusivas. Infere-se que ocorre o mesmo que na carne bovina: a fiscalização da certificadora é esporádica, porém rígida. Outro fator de incerteza é que as empresas que produzem orgânico e convencional precisam ter controle muito preciso da origem da matéria-prima e do seu processamento para evitar problemas de contaminação na industrialização e prejuízos com a comercialização do produto como convencional.

Deste modo, também tendo como base a conceituação de Campo, podese concluir que o cultivo e o processamento de açúcar orgânico também se caracterizam como um Campo Organizacional.

Quanto à distribuição dos ganhos advindos da produção de açúcar orgânico, esta também apresenta problemas. Sabe-se que a formação de preço da matéria-prima no setor sucroalcooleiro se dá de acordo com o sistema Consecana, em que se parte dos preços e mix de produtos da usina para calcular o valor a ser pago aos fornecedores de cana.

Este sistema tem sido questionado pelos fornecedores de cana que afirmam ter dificuldade de saber o real mix das usinas e os preços recebidos na comercialização dos produtos e assim não sabem se estão recebendo de forma justa ou não. Eles também apontam que o sitema não leva em conta a venda de subprodutos. Desta forma, nas usinas que produzem orgânicos, os fornecedores podem estar recebendo menos do que deveriam, pois podem ocorrer comportamentos oportunistas da empresa no pagamento da matériaprima, diminuindo a margem de comercialização destes, comprometendo a consolidação do Campo Organizacional deste segmento específico.

\section{Conclusão}

O mercado de produtos orgânicos vem se expandindo nos últimos anos, principalmente devido aos problemas sanitários com alimentos, que fez com que os consumidores passassem a exigir uma maior qualidade e segurança do alimento, respeitando o meio ambiente, ou seja, com produção baseada em sistemas agroecológicos, que envolve um manejo equilibrado dos recursos naturais.

Observa-se que tanto na produção de açúcar orgânico quanto de carne bovina orgânica, é necessário desintoxicar o solo e substituir os fertilizantes químicos por compostos orgânicos, sendo o controle de pragas feito por meio de técnicas de controle biológicos e naturais, estando, assim, de acordo com os princípios da produção orgânica.

Nota-se que todas as empresas frigoríficas produzem carne orgânica e convencional, mas no caso das usinas de açúcar, há aquelas que produzem só orgânico e aquelas que produzem açúcar orgânico e convencional. Assim, é necessário um planejamento da produção para aquelas que produzem ambos os tipos. Na produção da carne bovina orgânica, os animais orgânicos são abatidos e desossados antes que os convencionais. No caso da produção de açúcar orgânico verifica-se a existência de gerências de produção de orgânicos diferentes: intercalação da produção de açúcar orgânico com o convencional, que exige que durante 6 horas a cana orgânica produza açúcar que será vendido como convencional; produção de açúcar orgânico em uma só batelada no início ou no final da safra.

Verifica-se que as produções de carne orgânicas e de açúcar orgânicas formam Campos Organizacionais dentro das respectivas Cadeias Produtivas, pois além de atenderem às instituições comuns a todas as empresas, à legislação sanitária, trabalhista e fiscal, são submetidas à regulação e incentivo específicos - regras de certificação e da legislação federal de orgânicos - frutos dos interesses e estratégias dos diversos agentes envolvidos (produtores, certificadores, consumidores, Estado, entre outros).

Ressalta-se que neste trabalho foi possível constatar que a fiscalização das certificadoras é esporádica, porém realizadas de forma rígida, com forte enforcement por parte daquelas, deixando evidente a impossibilidade da mistura do produto convencional com o orgânico, não conduzindo, dessa forma, à incerteza quanto às características e origem da carne, o que daria brecha a comportamentos oportunistas.

Porém, a distribuição desigual dos ganhos obtidos com a comercialização de açúcar e carne orgânicos, principalmente em relação à baixa margem recebidas pelos produtores, pode levar a inviabilização do Campo Organizacional pela falta de oferta das respectivas matérias-primas orgânicas. Este aspecto fica evidente pela afirmação do representante da ASPRANOR 
de que a diferença de preço entre os orgânicos e convencionais fica em um patamar entre 7 e $20 \%$.

\section{Referências:}

BNDES SETORIAL. Agricultura orgânica: quando o passado é futuro. Rio de Janeiro, n.15, p. 3-34, 2002.

FLIGSTEIN, N. The transformationof corporate control. Cambridge: Harvard University Press, 1990.

FLIGSTEIN, N. Markets as politics: a political-cultural approach to market institutions. American Sociological Review, v.61, p.656-673, agosto 1996.

INSTITUTO BIODINÂMICO - IBD. Disponível em: www.ibd.com.br. Acesso em 03 mar. 2005.

PORTER, M. Estratégia competitiva. Rio de Janeiro: Campus, 1986. 362 p.

POWELL, W.W.; DIMAGGIO, P.J. The new institucionalism in

organizacional analysis. Chicago: The University of Chicago Press, 1991.

STOREL JÚNIOR, A. A potencialidade do mercado de açúcar orgânico para a agroindústria canavieira do Estado de São Paulo. 2003. 150p. Dissertação (Mestrado em Desenvolvimento Econômico, Espaço e Meio Ambiente) - Instituto de Economia, Unicamp, Campinas, 2003.

VIAN, C.E.F. Expansão e diversificação do complexo agroindustrial sucroalcooleiro no centro-sul do Brasil - 1980/96. 1997. Dissertação (Mestrado em Engenharia de Produção) - Departamento de Engenharia de Produção, Universidade Federal de São Carlos, São Carlos, 1997.

VIAN, C.E.F.; SILVA, P.R.C.; PINOTTI, L.R. Informática e terceirização de serviços no setor sucroalcooleiro. In: ENEGEP, 16, 1996, Piracicaba. Anais..., Piracicaba, 1996.

VIAN, C.E.F. Agroindústria canavieira: estratégias competitivas e modernização. Campinas: Átomo \& Alínea, 2003.

WILLIAMSON, O. The economic institutions of capitalism. New York: F. Press, 1985.
WILLIAMSON, O. Transction cost economics. In: SCHMALENSEE, R.; WILLIG, R. (Orgs.) Handbook of industrial organization. Amsterdã: North-Holland, p.135-182, 1989.

WILLIAMSON, O. Organization theory: from chester Barnard to the Present and Beyond. New York: Oxford Universiy Press, 1990.

WILLIAMSON, O. Transction cost economics and organization theory. Industrial and Corporate Change, Oxford, v.2, n.2, p.107-156, 1993.

WINTER, M. Rural politics: policies for agriculture, forestry and environment. Londres: Routledge, 1997.

WOOMACK, J.P. el al. A máquina que mudou o mundo. 4.ed. Rio de Janeiro: Campus, 1992.

ZYLBERSZTAJN, D. Governance structures and agribussiness coordination. A transaction cost economics based approach. In: GOLDBERG. R.

Research in domestic and international agribussiness management. Cambridge: Harvard University: JAI Press, 1996.

\section{Resumo:}

Este trabalho analisa a dinâmica atual da produção de carne bovina e açúcar orgânicos, demonstrando as especificidades da organização interna das empresas e a necessidade de coordenação das atividades, desde o campo até a venda ao consumidor final. Utiliza-se como referencial teórico o conceito de "Campo Organizacional". As informações foram coletadas por questionários enviados aos frigoríficos, às usinas, à principal certificadora e à associação de produtores de bovinos orgânicos. Conclui-se que a produção de carne e açúcar orgânicos formam Campos Organizacionais dentro das respectivas Cadeias Produtivas, pois estão submetidas à regulação e incentivo específicos - regras de certificação e da legislação federal de orgânicos - frutos dos interesses e estratégias dos diversos agentes envolvidos. Porém, distribuição a desigual dos ganhos obtidos com a comercialização de açúcar e carne orgânicos, principalmente em relação à baixa margem recebidas pelos produtores, pode levar a inviabilização do Campo Organizacional pela baixa oferta das respectivas matérias-primas orgânicas.

\section{Palavras-chave:}

Campo Organizacional, Açúcar Orgânico, Carne Bovina Orgânica, Certificação. 